\title{
INFLUENCE OF VELOCITY GRADIENT ON OPTIMISATION OF THE AGGREGATION PROCESS AND PHYSICAL PROPERTIES OF FORMED AGGREGATES
}

\author{
Part 1. Inline high density suspension (IHDS) aggregation process
}

\section{PAVEL POLÁŠEK}

Institute of Hydrodynamics, AS CR, v. v. i., Pod Patankou 5, 16612 Prague 6, Czech Republic; Mailto: polasek@ih.cas.cz

This paper deals with optimisation and acceleration of the clarification process. It was established that both these objectives are closely inter-related and can be accomplished by the formation of aggregates with a high agitation intensity until the flocculation optimum is reached. This is a new method of formation of aggregates which is called the Inline High Density Suspension (IHDS) formation process. Further, under the IHDS process the aggregates are formed with a single root-mean-square velocity gradient $\bar{G}>>50 \mathrm{~s}^{-1}$. It was also established that the process of formation of aggregates (expressed by residual value of the observed determinant) passes through a minimum. This minimum is considered to be the flocculation optimum. Furthermore, the agitation intensity $(\bar{G})$ was found to be the inherent means influencing compactness and thereby density of the aggregates formed. This proves the vital role of agitation intensity on the morphological and physical properties of aggregates formed. The resultant aggregates formed by the IHDS process are very compact, dense and homogeneous in their size, shape, volume and inner structure. Last but not least, the IHDS process applied to the HR-CSAV type sludge blanket clarifier facilitated its high attainable upflow velocity above of $25 \mathrm{~m} \mathrm{~h}^{-1}$.

KEY WORDS: Flocculation Optimum, Inline High Density Suspension (IHDS) Formation Process, Properties of Aggregates, Intensity of Agitation, Velocity Gradient $\bar{G}$.

Pavel Polášek: VLIV RYCHLOSTNÍHO GRADIENTU NA OPTIMALIZACI AGREGAČNÍHO PROCESU A VLASTNOSTI VYTVOŘENÝCH AGREGÁTŮ. Část 1. Průtoková tvorba vysoce hustotní suspenze. J. Hydrol. Hydromech., 59, 2011, 2; 36 lit., 8 obr., 2 tab.

Článek se zabývá optimalizací a zrychlením čiřícího procesu. Bylo zjištěno, že oba tyto cíle spolu úzce souvisí a může jich být dosaženo tvorbou agregátů probíhající s vysokou intenzitou míchání pomocí procesu Inline High Density Suspension (IHDS). Za podmínek metody IHDS probíhá tvorba agregátů při vysokých rychlostních gradientech $\bar{G} \gg 50 \mathrm{~s}^{-1}$, a to až do ukončení jejich tvorby ve flokulačním optimu. Bylo prokázáno, že tvorba agregátů prochází minimem, které je možné považovat za flokulační (agregační) optimum. Dále bylo zjištěno, že intenzita míchání $(\bar{G})$ je přirozeným prostředkem ovlivňujícím kompaktnost a tím rovněž hustotu vytvořených agregátů. Výsledné agregáty vytvořené IHDS procesem jsou velmi kompaktní, husté s homogenní velikostní distribucí, mají pravidelný tvar a uspořádanou vnitřní strukturu. Aplikace IHDS procesu v HR-ČSAV čiřičích umožňuje jejich provoz při vzestupné rychlosti přesahující $25 \mathrm{~m} \mathrm{~h}^{-1}$ a celkové době zdržení necelých 12 minut.

KLÍČOVÁ SLOVA: flokulační optimum, průtoková tvorba vysoce hustotní suspenze, vlastnosti agregátů, intenzita míchání, rychlostní gradient.

\section{Introduction}

The process of aggregate-destabilisation of the particles of impurities is affected by the chemical factors (reaction conditions) and the formation of aggregates from the destabilised particles is affected by the physical factors (agitation conditions).
Great attention was given to researching the mechanisms and the kinetics of formation of flocculent suspension (Smoluchovski, 1917; Camp and Stein, 1943; Camp, 1946, 1953, 1968; Hudson, 1965, 1973; Harris et al., 1966; Swift and Friendlander, 1965; Soucek and Sindelar, 1967; Ives, 1978; Ham and Christman, 1969; Parker et al., 
1972; Tambo and Watanabe, 1979; Polasek and Van Duuren, 1979; Hereit et al., 1980, 1983; Spicer and Pratsinis, 1996; Van Duuren 1997; Ducoste and Clark, 1998). The attention of most researchers was primarily directed to study the process kinetics.

The agitation conditions, i.e. agitation intensity, characterised by the root-mean-square velocity gradient $\bar{G}$ (Camp and Stein, 1943), its duration and distribution of a velocity field in the total volume of agitated water facilitates the formation of readily separable aggregates.

The significance of agitation conditions characterised by the root-mean-square velocity gradient $\bar{G}$ on the process of formation of aggregates and their properties is not yet fully understood. Therefore, the engineer's approach to the designing of flocculation plants is not unified. Based on American practice Camp (1953) states that the velocity gradient varies between $\bar{G}=20-74 \mathrm{~s}^{-1}$. Fair and Geyer (1958) suggest the optimum velocity gradient to be in the range between $\bar{G}=30-60 \mathrm{~s}^{-1}$. However, they accept that the initial velocity gradient, applied at the beginning of the aggregation process, could be as high as $100 \mathrm{~s}^{-1}$ and recommend that the final velocity gradient, at the end of the flocculation process, should not exceed $\bar{G}=10 \mathrm{~s}^{-1}$ (tapered flocculation). Similarly, Ritchie (1965) states that the optimum value of the velocity gradient for clay particles should be within the range between $\bar{G}=7-11 \mathrm{~s}^{-1}$. In contrast, Walker (1968) is of the opinion that the flocculation of surface waters can take place at a velocity gradient as high as $\bar{G}=175 \mathrm{~s}^{-1}$. Based on everyday practice, Hudson (1965) states that a velocity gradient $\bar{G}=10$ $-15 \mathrm{~s}^{-1}$ seems to be the most accepted in mechanically agitated flocculation chambers, while $\bar{G}>40 \mathrm{~s}^{-1}$ tends to produce flocs of a relatively low settling velocity. Generally, this concept of agitation intensity prevails to-date (Schutte, 2006).

Only recently, Lawler (2000) came to the conclusion that " $\bar{G}$ stands for gentle". This opinion is in agreement with previous work of Han and Lawler (1991, 1992), who wonder if mixing has any significant role in particle aggregation at all. They came to the conclusion that the importance of the velocity gradient (shear) had been overemphasized in the traditional philosophy of flocculation and that the velocity gradient has far less significance than previously thought. Furthermore, they suggest that the primary importance of agitation is to keep particles in suspension so that their collisions can occur by differential sedimentation and that the secondary role of agitation is only to provide the velocity gradient for collisions between particles $>1 \mu \mathrm{m}$ and of nearly the same size. They concluded that the velocity gradient although by no means irrelevant, is relatively unimportant in flocculation. Based on the above, Thomas et al. (1999) states that it is generally accepted that previous work of Camp and Stein has overestimated the importance of root-mean-square velocity gradient $\bar{G}$. From this statement it is evident that the significance of the root-mean-square velocity gradient $\bar{G}$ for the development of flocculent suspension is not yet fully appreciated even though it remains a key design parameter in flocculation modelling.

The significance of the influence of a high velocity gradient $\bar{G}>50 \mathrm{~s}^{-1}$ and its duration on the course of the aggregation process, its kinetics and the physical and morphological properties of aggregates formed such as their size, shape, volume, compactness, strength and density, which affect their settleability, is not yet adequately researched. Therefore, the aim of this study is to establish the influence of hydrodynamic conditions on:

a) the optimisation and the acceleration of the aggregation process with respect to sedimentation of the aggregates formed,

b) the number and size of aggregates formed, and

c) the physical properties of aggregates formed.

In the initial phase of the study the effects of high velocity gradients $\bar{G}>50 \mathrm{~s}^{-1}$ on the course, optimisation and acceleration of the aggregation process were investigated, while the evaluation of objectives in (b) and (c) above were based on observation. The quantification of these two objectives under the conditions of low intensity agitation was carried out in the second research phase and the findings thereof are described in Part 2 of this paper.

Due to a variety of mechanisms that may be encountered in the transformation of impurities present in water into separable suspension the term coagulation does not reflect the basis of all partial processes taking place during the transformation of all kinds of colloidal impurities into readily separable flocs. It is more accurate to call this process aggregation and the flocs formed aggregates and the reagent used destabilisation agent instead of coagulant. In this context the terms aggregation, aggregates and destabilisation agent are used in this paper. 


\section{Jar test studies}

The influence of the agitation intensity characterised by the root-mean-square velocity gradient $\bar{G}$ and its duration $T$ on the course of the aggregation process and the morphological and physical properties of the formed aggregates was studied by jar tests. The effect of different $\bar{G}$ applied over different times $T$ on the settleability of aggregates formed was investigated by direct measurement whilst the influence of different $\bar{G}$ and $T$ on the physical properties of the formed aggregates could only be evaluated indirectly based on the changes in their sedimentation kinetics. This was considered adequate for meeting the initial objectives of the project.

The jar tests were carried out with hydrolysing destabilisation reagents $\left(\mathrm{Fe}^{3+}\right.$ and $\mathrm{Al}^{3+}$ salts) under optimised reaction conditions as well as aggregation reagents (different cationic polyelectrolytes CPE), namely Floccotan and Superfloc SF-577. Floccotan is a partially condensed product of the commercial wattle tannin extract treated to produce active amine groups along the polymerised molecule. Superfloc 577 is a polyquarternary amine type cationic polymer.

A standard Phipp \& Bird 6-station flocculator was used. The jar tests were carried out in 2 litre standard Pyrex beakers containing 1.5 litres of water. A dual, double vertical blade type stirrer was used in all jar tests. The velocity gradient $\bar{G}$ generated by this stirrer was calculated from the torque measured as follows: A bending beam strain gauge was used to measure the effect of the reaction force resulting from the rotating stirrer and transmitted via the water on the wall of the beaker. The resulting torque $M$ is the product of the circumferential force and the beaker radius. The stirrer $R P M$ was displayed on the stirrer drive. The power input shaft to water was calculated as follows

$$
\begin{aligned}
& P_{S W}=\frac{R P M_{S} M}{9550} \quad[\mathrm{~mW}] \\
& \bar{G}=\sqrt{\frac{P_{S W}}{V \mu}}\left[\mathrm{s}^{-1}\right] .
\end{aligned}
$$

The conversion of the stirrer $R P M$ to the velocity gradient $\bar{G}\left(G^{*}\right)$ is shown in Fig. 1.

The following jar tests procedure was used. Reaction beakers, each containing the optimised dosage of destabilisation (aggregation) reagent, were placed in the flocculator. Another set of beakers filled with 1.5 litres of raw water were placed next to the reaction beakers. Water from the set of raw water beakers was then quickly poured into all beakers containing destabilisation agent in order to produce its dispersion and homogenisation of the destabilisation agent with the raw water. The flocculator was then switched-on, all stirrers brought up to the maximum speed and the position of individual beakers readjusted to produce the smallest vortex and smooth water surface in each beaker. This operation was completed within a few seconds. Then the stirrer speed was reduced to the $R P M$ generating the required $\bar{G}$. At the end of the aggregation process the stirrer was pulled out from the particular beaker. The aggregation time was the running time of the stirrer. The sedimentation time was measured from the moment the stirrer was switched-off and pulled out from the beaker.

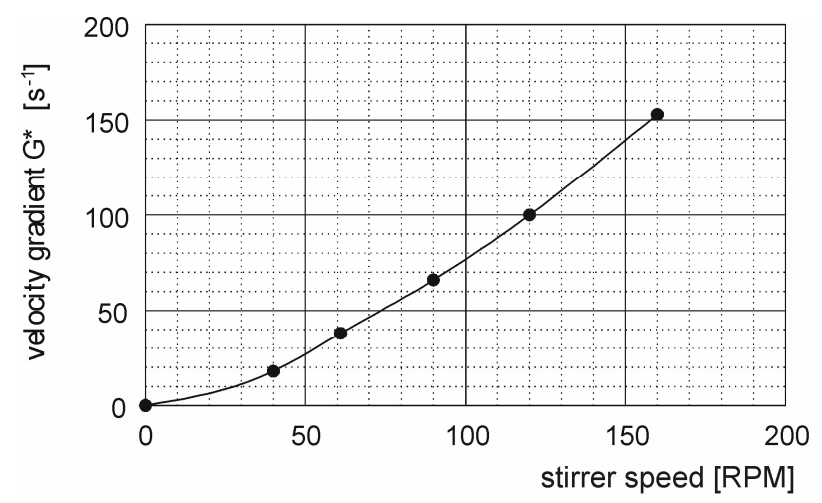

Fig. 1. Conversion of stirrer speed to root-mean-squate velocity gradient $\mathrm{G}^{*}$.

\section{Methods}

A great number of studies by various researchers were carried out with synthetic suspensions in the past. The use of synthetic suspension is considered problematic from the point of view of the validity of conclusions in every day engineering practice with respect to the designing and operation of waterworks. The surface waters contain natural mineral and organic pollutants of different types and concentrations and their resultant synergy effect cannot be simulated by simple synthetic suspensions. Therefore, this research was carried out with raw waters from different surface sources (Tab. 1). The results presented herein were obtained with the Saulspoort Dam water only as similar results were also obtained on the other localities.

The quality of the purified water was evaluated by the residual turbidity. In certain cases when fer- 
$\mathrm{T}$ a b 1 e 1 . The average quality of different raw waters used in the study.

\begin{tabular}{lcccc}
\hline Determinant & Units & Vaal dam & Loch Athlone dam & Saulspoort dam \\
\hline Temperature & {$\left[{ }^{0} \mathrm{C}\right]$} & 18 & $12-25$ & $12-25$ \\
pH & {$[-]$} & 8.2 & 7.7 & $7.4-8.2$ \\
Turbidity & {$[\mathrm{NTU}]$} & 160 & $50-690$ & $30-250$ \\
Colour & {$\left[\mathrm{mg} \mathrm{Pt} \mathrm{l}^{-1}\right]$} & 17.5 & $5-15$ & $10-40$ \\
Total hardness & {$\left[\mathrm{mg} \mathrm{CaCO}_{3} 1^{-1}\right]$} & 71 & 108 & $90-160$ \\
Total alkalinity & $\left.\left[\mathrm{mg} \mathrm{CaCO}_{3}\right]^{-1}\right]$ & 65 & 75 & $75-140$ \\
THM - potential value & {$\left[\mu \mathrm{g} \mathrm{CHCl}_{3} l^{-1}\right]$} & - & - & 878 \\
COD & {$\left[\mathrm{mg} \mathrm{O}_{2} l^{-1}\right]$} & 4.2 & 3.4 & 6.5 \\
\hline
\end{tabular}

ric chloride or aluminium sulphate was used, the residual $\mathrm{Fe}$ or $\mathrm{Al}$ was also measured. The jar tests were carried out with different, but constant stirrer speeds employed over the entire aggregation time $T$ required. The samples of purified water were pipetted out from the centre of the beakers, approximately $30 \mathrm{~mm}$ below the water surface. The samples were usually taken either after $1,3,5,10$ and 30 minutes or after 2, 5, 10 and 30 minutes of sedimentation.

The effect of conditions of agitation on the properties of aggregates formed and their settleability was evaluated by changes in the content of cation of added coagulant $(\mathrm{Me})$ and turbidity $(\mathrm{Tu})$ - affix $\mathrm{F}$ means that all separable particles were removed by centrifugation and only the non-separable particles remained in the analysed sample. The residual content of non-separable particles was measured because it determines the attainable efficiency of the purification process. The residual content of organic matter is not stated because its influence on the process of formation of aggregates and their settleability is incorporated in the residual $\mathrm{Tu}$ and Me values. Turbidity was measured by photometers and Me photocolorimetrically. The aggregate-size distribution of the formed aggregates was measured by the test of aggregation and the removal of impurities by the attained and attainable separation efficiency (Hereit et al., 1977). The pattern of Tu and Me results is very similar and therefore only the results of turbidity measurements are included in this paper.

\section{Result and discussion}

The jar test study was carried out based on the presumption that the strength of the bond between particles is determined by the ratio between the adhesion and tangential forces acting upon the particles during their collisions and such bond is holding the particles together in the aggregates being formed. Using natural raw water the magnitude of the adhesion forces is governed by the attained degree of destabilisation of the particles of impurities which is determined by the dosage of the destabilisation agent. All jar tests were carried out with the optimised dosage of destabilisation (aggregation) agent. Therefore, it is assumed that the degree of destabilisation achieved was the same and hence the magnitude of the binding forces by which the particles mutually act on one another can also be considered to be the same. Thus, the only operational variables are the magnitude of tangential (shear) forces (characterised by $\bar{G}$ ) and the time of their action $T$.

It should be pointed out that at the commencement of sedimentation settling of the aggregates was impeded owing to the run-out rotation of the water. Naturally, the effect of this impediment increased with higher stirrer $R P M$ but was the same in all beakers agitated with the same $R P M$. The runout rotation of water created a short time side effect of gradually diminishing agitation intensity (tapered flocculation) acting on the formed aggregates thus allowing them to grow into larger and hence more rapidly settleable aggregates. The purpose of taking the first samples of purified water after 1 or 2 minutes of sedimentation was to establish the effect of different $\bar{G}$ and $T$ on the development of the aggregates and the trend in their settleability which would otherwise remain unnoticed as it diminishes with sedimentation time.

\subsection{Flocculation optimum and character of formed aggregates}

The influence of various $\bar{G}$ applied over different time $T$ on the course of the development of flocculent aggregates formed with ferric chloride and their sedimentation kinetics is shown in Figs. 2 to 6 .

Fig. 2 shows the effect of the dynamics of the aggregation process on the aggregates formed with various single $\bar{G}$ applied over different times $T$. 
Similar results were obtained with aluminium sulphate, Floccotan and SF-577 formed aggregates but their optimum agitation time $T$ were different however.

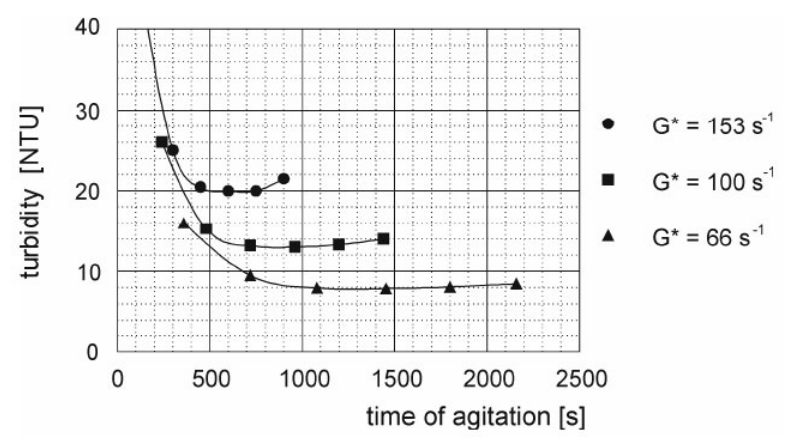

Fig. 2. $\mathrm{FeCl}_{3}$ : Flocculation optimum for different $\mathrm{G}^{*}$ (after 1 minutes sedimentation).

Since all the individual aggregation curves shown in Fig. 2 are laden with the same side effect of the run-out rotation of the water, it can be assumed that these curves illustrate a true representation of the influence of various $\bar{G}$ applied over different $T$ on the kinetics of the aggregation process and the character of formed aggregates.

The path of the aggregation curves in Fig. 2 is illustrated by residual turbidity measured after 1 minute sedimentation. As it is evident from this Figure, the aggregation process is characterised by a change in the number (concentration) of aggregates in the system which is influenced by the dynamics of aggregates development. The development of aggregates can be described as follows. At the beginning of aggregation, when there are still relatively a few aggregates formed and the number of particle collisions is high, the intensive combining of the particles into aggregates takes place at the expense of the total number of particles. Therefore, the total number of both particles and aggregates formed decreases rapidly irrespective of $\bar{G}$ employed. This is evident by a steep drop in the residual turbidity at short agitation time $T$. As aggregation progresses with increasing agitation time the aggregates being formed enlarge in size and their total number decreases. As a result, the rate of aggregation gradually slows down to a range of $T$ at which the lowest residual turbidity is achieved. This is evident by a gradual flattening of the aggregation curves. When the formation of aggregates is completed, the residual turbidity reaches its minimum. This minimum is considered to be the optimum of the aggregation process, hereinafter re- ferred to as the flocculation optimum (Soucek and Sindelar, 1967), expressed by optimum $T$ for the $\bar{G}$ employed.

Furthermore, Fig. 2 also shows the flocculation optimum is not obtained at the same $T$ for different $\bar{G}$ but it is $\bar{G}$ dependent. The shortest optimum $T$ is always obtained with the highest $\bar{G}$ employed and $T$ is not inversely proportional to $\bar{G}$, i.e. optimum $\bar{G} T \neq$ const. - this topic will be addressed in a separate paper.

As the aggregates being formed enlarge in size the number of primary aggregates and smallest micro-aggregates gradually decreases. Since the system aggregating in beaker is a fully mixed system the aggregates being formed are randomly transferred throughout the beaker, where $\bar{G}$ varies from its highest magnitude at tip zone of the stirrer to its lowest value at the part of the bulk zone that is most remote from the stirrer. As soon as an aggregate formed in the zone of lowest intensity of agitation moves into the zone of higher intensity of agitation such aggregate is too large to withstand the greater shear in this zone and fragments. From the fragmented parts new aggregates are formed. It was observed that the aggregates formed with a higher $\bar{G}$ were smaller, but more uniform in their size than those formed with a lower $\bar{G}$.

It is assumed that when the flocculation optimum is reached all destabilised particles are aggregated. Aggregation prolonged considerably beyond the flocculation optimum resulted in a gradual and very slow rise in residual turbidity. This could result from surface erosion/fragmentation of the aggregates caused by an extended influence of the tangential forces, which may cause gradual fatigue of the bonds holding together the destabilised particles in aggregates. Alternatively, this could also result from inner restructuring of the particles of impurities in the primary aggregates which are formed during the perikinetic phase of aggregation and of which the resultant aggregates are formed. As a result, a considerably over-aggregated system starts to contain aggregates of a poorer settleability than the system with the aggregates formed at the flocculation optimum. The actual reason for this increase in residual turbidity necessitates a further investigation.

The optimum agitation time $T$ for the aggregates formed with $\bar{G}=153 \mathrm{~s}^{-1}$ when purifying Saulspoort Dam water was determined with sufficient accuracy for the purpose of practical engineering as follows: $T=340 \mathrm{~s}$ for aluminium sulphate, 
$T=620 \mathrm{~s}$ for ferric chloride, $T=750 \mathrm{~s}$ for Flocco$\tan$ and $T=1000 \mathrm{~s}$ for Superfloc SF-577.

Typical path of aggregation curves of the Fe- aggregates formed with $\bar{G}=100 \mathrm{~s}^{-1}$ over different $T$ is dependent on sedimentation time as shown in Fig. 3. The same pattern was established also for the Al- and the CPE-formed aggregates as well as for the aggregates formed with various $\bar{G}$. The residual turbidity dropped to lower values with sedimentation time, thus considerably reducing the great differences in residual turbidity between the under- and over-aggregated regions measured at the beginning of sedimentation. The differences in residual turbidity measured in samples taken after 30 minutes of sedimentation from which all remaining separable particles were removed by centrifugation (Hereit et al., 1977) and which are evident from the centrate curve indicate the true impact of the $\bar{G}$ and $T$ on attainable clarity of the purified water. The differences in residual turbidity between low and high $T$ are minimal which proves the raw water was purified with high aggregatedestabilisation efficiency.

The importance for the aggregation process to be carried out to within its flocculation optimum is also evident from Fig. 3. The residual turbidity produced by the non-separable particles only, as illustrated by the "centrate" curve, reflects the quality to which the water is purifiable with the same $\bar{G}$ over different agitation times. It is evident from this Figure that the kinetics of sedimentation improves and destabilisation of the particles of impurities enhances with increasing $T$ up to the flocculation optimum. The aggregation process extending beyond the optimum agitation time does not improve either the kinetics of sedimentation of the formed aggregates or the purified water clarity. It results mainly in a waste of energy.

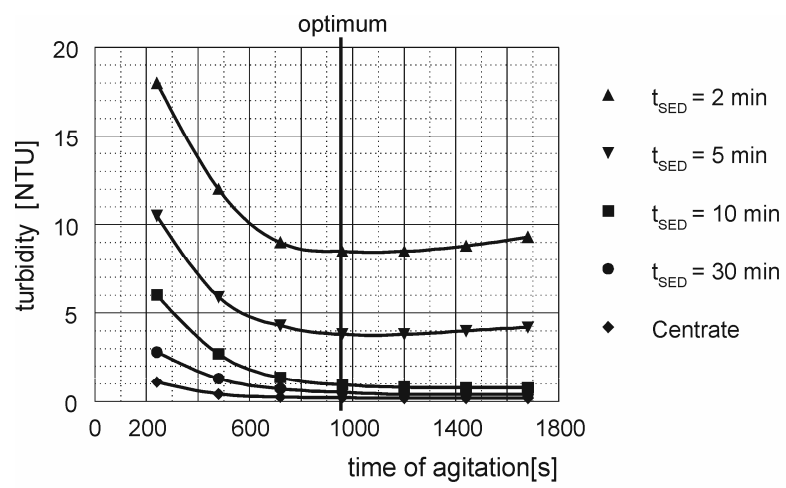

Fig. 3. Flocculation optimum - influence of sedimentation time (Loch Athlone Dam, $\mathrm{FeCl}_{3}, \mathrm{G}=100 \mathrm{~s}^{-1}$ ).
Comparison of the kinetics of sedimentation of the aggregates formed with the same $\bar{G}$ over different agitation time corresponding to approximately 0.5 to 1.5 times the optimum $T$ is shown in Fig. 4. The most rapidly settling aggregates were formed when the aggregation process ended at the flocculation optimum. Slightly poorer settleable aggregates were formed beyond the flocculation optimum at 1.5 times optimum $\mathrm{T}$. The residual turbidity of these two tests equalled after approximately 10 minutes of sedimentation. As expected, the aggregation process that ended only at 0.5 times optimum $\mathrm{T}$ produced aggregates of poorer settleability. The clarity of the purified water was also slightly poorer as is evident from the comparison of the residual turbidity after 30 minutes of sedimentation. Since the aggregates were formed with the same $\bar{G}$, differences in the residual turbidity measured at the beginning of sedimentation for different $T$ reflects differences in the sedimentation velocities of the aggregates formed over such different agitation times.

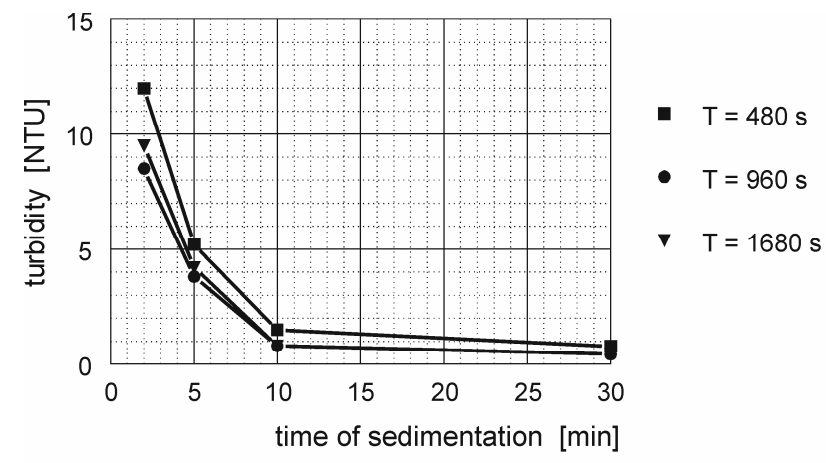

Fig. 4. Significance of agitation time on kinetics of sedimentation of aggregates formed with the same $\mathrm{G}^{*}$ (Loch Athlone Dam, $\mathrm{FeCl}_{3}, \mathrm{G}^{*}=100 \mathrm{~s}^{-1}$ ).

The significance of low intensity agitation on the settleability of aggregates is evident from the comparison of results shown in Figs. 5 and 6. Fig. 5 shows the sedimentation kinetics of the microaggregates formed with various single $\bar{G}$ and Fig. 6 of the macro-aggregates developed from these micro-aggregates during the subsequent low intensity agitation with $\bar{G}=10 \mathrm{~s}^{-1}$ for a period of 3 minutes. The comparison of the sedimentation curves in Fig. 5 shows that the settleability of the aggregates formed with a higher $\bar{G}$ is lower in the initial phase of sedimentation than that of the aggregates formed with a lower $\bar{G}$ while no difference in the residual turbidity was measured after 30 minutes of sedimentation irrespective of $\bar{G}$. It 
should be pointed out that sedimentation of aggregates in its initial phase is impeded, to large extent, by run-out rotation of the water which is more intensive and longer lasting in the case of a higher $\bar{G}$. Therefore, the actual difference in settleability of the aggregates formed is considerably smaller than that shown in Fig. 5. As the side effect of the run-out rotation of the water the tapering intensity agitation assisted the micro-aggregates to aggregate into macro-aggregates of approximately the same size. As it is evident from Fig. 6 the aggregates produced from the micro-aggregates formed with a higher $\bar{G}$ settled more rapidly than those formed with a lower $\bar{G}$.

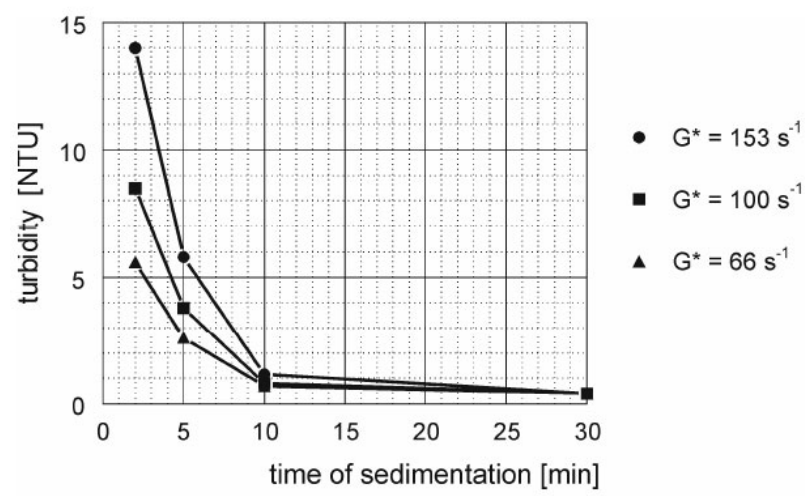

Fig. 5. Influence of $\mathrm{G}^{*}$ on kinetics of sedimentation of IHDS formed micro-aggregates (Loch Athlone Dam, $\mathrm{FeCl}_{3}$, optimum $T$ ).

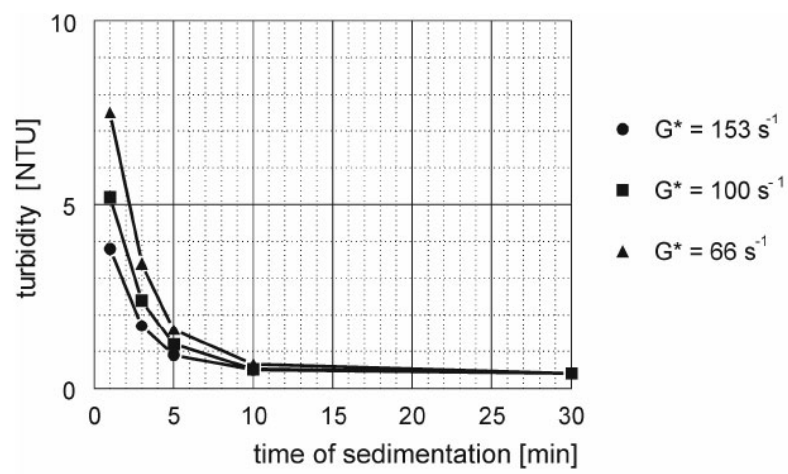

Fig. 6. Influence of $\mathrm{G}^{*}$ on kinetics of sedimentation of IHDS formed aggregates after low intensity agitation (Loch Athlone Dam, $\mathrm{FeCl}_{3}$, optimum $T$ ).

The rate at which aggregates settle at the beginning of sedimentation is decisive for the acceleration of the sedimentation process. Fig. 7 compares the settleability of aggregates formed with high agitation intensity $\bar{G}_{H}$ with and without being further aggregated by low agitation intensity with $\bar{G}_{L}$ with the settleability of aggregates formed by the accustomed flocculation conditions $\left(\bar{G}<50 \mathrm{~s}^{-1}\right)$. The formation of micro-aggregates took place with $\bar{G}_{H}=100 \mathrm{~s}^{-1}$ up to the optimum $T$. This was followed by low agitation intensity with $\bar{G}_{L}=10 \mathrm{~s}^{-1}$ for an additional period of 3 minutes, allowing the micro-aggregates to develop into macro-aggregates. The formation of aggregates by flocculation under the accustomed conditions of agitation was carried out with $\bar{G}=19 \mathrm{~s}^{-1}$ for a period of 15 minutes followed by agitation with $\bar{G}=10 \mathrm{~s}^{-1}$ for an additional period of 3 minutes. Since the resultant macro-aggregates were formed under the same $\bar{G}_{L}$ it is assumed they are of the same size. Therefore, the differences between the residual turbidity at the beginning of sedimentation are proportional to the differences in the density of the micro-aggregates formed under different agitation intensity. Comparison of residual turbidity shows that the sedimentation velocity of the macro-aggregates formed from the micro-aggregates developed with a high $\bar{G}$ is considerably higher than that of the aggregates formed under the accustomed agitation conditions with a low $\bar{G}$.

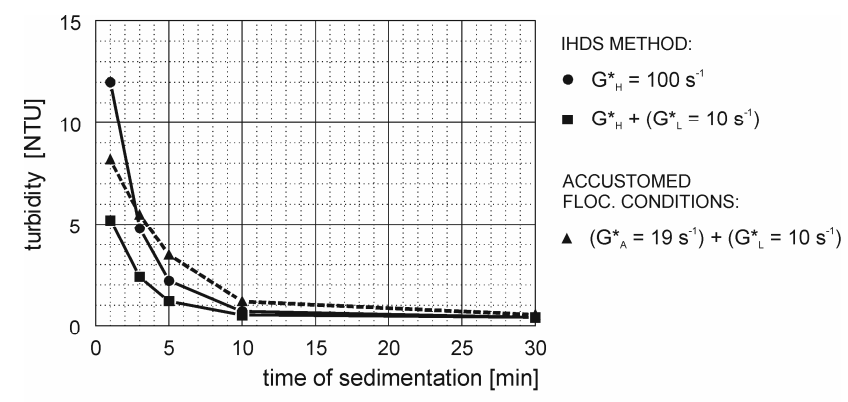

Fig. 7. Comparison of kinetics of sedimentation of aggregates formed by IHDS and accustomed flocculation conditions (Loch Athlone Dam, $\mathrm{FeCl}_{3}$, optimum T).

\subsection{The inline high density suspension (IHDS) aggregation process}

The method of formation of flocculent suspension taking place with a high agitation intensity $\bar{G}_{H}>50 \mathrm{~s}^{-1}$, but preferably between $\bar{G}_{H}=100-$ $400 \mathrm{~s}^{-1}$ through the entire aggregation process up to the flocculation optimum is reached is known as the Inline High Density Suspension (IHDS) method (Polasek 1970, 1972, 2007; Polasek and Mutl 1995b, 2005a, 2005b). The $\bar{G}>400 \mathrm{~s}^{-1}$, even though applicable, was found to have no practical 
or economical benefit. The resultant aggregates formed by the IHDS method are compact and dense aggregates well homogenised in their size, volume and density. The IHDS method is illustrated in Fig. 8.

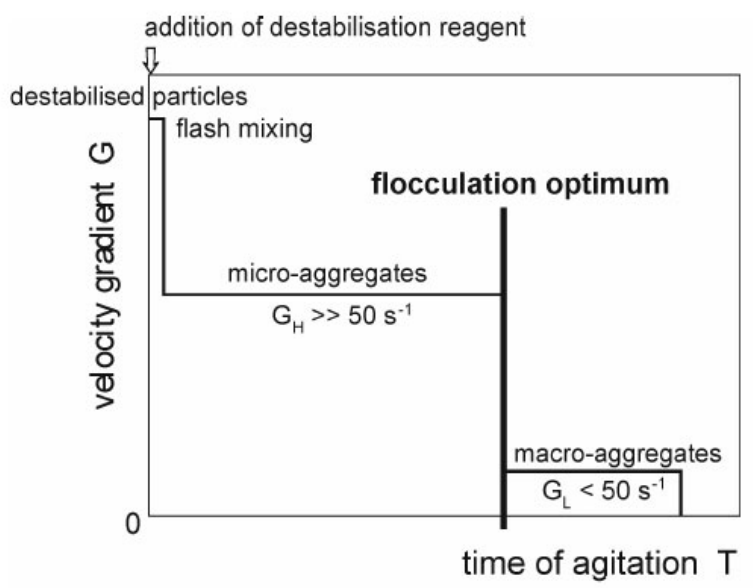

Fig. 8. Illustration of the inline high density suspension (IHDS) formation process.

When the formation of macro-aggregates that are readily separable by sedimentation is required, then the micro-aggregates formed are subsequently aggregated during low intensity agitation phase with $\bar{G}_{L}$ for a short time in order to enable the microaggregates to grow into macro-aggregates. The formation of macro-aggregates takes place with a $\bar{G}_{L L}<50 \mathrm{~s}^{-1}$, preferably $\bar{G}_{L}<10 \mathrm{~s}^{-1}$ over a short time.

It follows from the foregoing that the IHDS process affects very favourably those properties of aggregates that influence their settleability, such as shape, inner structure and density. It does not change the principles of aggregate formation, i.e. the need for aggregate-destabilisation of the particles of impurities and the mechanisms of formation of flocculent aggregates. High intensity agitation is the inherent means increasing the compactness and hence density of aggregates formed without need of applying any floc weighting substance.

\subsection{Acceleration of the water purification process}

The results obtained from jar tests and conclusions based thereon were verified in a full size plant $(\mathrm{PO}$ lasek 1980; Polasek and Van Duuren 1981; Polasek and Mutl, 2005a).

The important contribution of IHDS process for the acceleration of the water purification process as well as the quality of purified water is evident from comparison of operating conditions and performance results (Tab. 2) of different clarifier types installed at the Old Waterworks of the Bethlehem Municipality, namely Clariflocculator, Pretreator and HR-CSAV Clarifier. The Clariflocculator is a radial flow type sedimentation tank. The Pretreator is a type of clarifier combining radial and vertical flow in the sludge blanket. The HR-CSAV clarifier a vertical flow type with a fully fluidised sludge blanket incorporating the High Rate Clarification (HRC) technology which includes IHDS and POA processes (Polasek, 1980b; Polasek and Mutl, 2005a). The POA stands for post-orthokinetic agglomeration process by which the aggregates developed during flocculation process are subsequently agglomerated into very large agglomerates by means of organic flocculant aid (OFA) (Mutl, Polasek 2002; Polasek, 2005, 2009; Polasek and Mutl 2005b).

The results in Tab. 2 show that while the clarifiers were purifying the same raw water to approximately the same quality the conditions under which they operate are very different. The Clariflocculator was operated at an upflow velocity of $1.2 \mathrm{~m} \mathrm{~h}^{-1}$ and total retention time of about 4 hrs. The Pretreator was operated at an upflow velocity of about $1.5 \mathrm{~m} \mathrm{~h}^{-1}$ and total retention time of about $3.5 \mathrm{hrs}$.

Table 2. Comparison of operating conditions of different type clarifiers.

\begin{tabular}{|c|c|c|c|c|c|c|}
\hline \multirow{3}{*}{$\begin{array}{l}\text { Type of } \\
\text { clarifier }\end{array}$} & \multirow{2}{*}{$\begin{array}{l}\text { Retention } \\
\text { time in the } \\
\text { clarifier }\end{array}$} & \multirow{2}{*}{$\begin{array}{c}\text { Hydraulic } \\
\text { loading at } \\
\text { separation } \\
\text { Level }\end{array}$} & \multicolumn{2}{|c|}{ Dosing rate } & \multicolumn{2}{|c|}{ Turbidity } \\
\hline & & & $\mathrm{Al}_{2}\left(\mathrm{SO}_{4}\right)_{3}$ & SF-A110 & $\mathrm{C}$ & $\mathrm{CF}$ \\
\hline & {$[\mathrm{min}]$} & {$\left[\mathrm{m}^{3} \mathrm{~m}^{-2} \mathrm{~h}^{-1}\right]$} & {$\left[\mathrm{mg} \mathrm{l}^{-1}\right]$} & {$\left[\mathrm{mg} \mathrm{l}^{-1}\right]$} & {$[\mathrm{NTU}]$} & {$[\mathrm{NTU}]$} \\
\hline Raw water & & & & & 102 & 54 \\
\hline Pretreator & 210 & 1.5 & 60 & 0 & 7.1 & 1.5 \\
\hline Clariflocculator & 240 & 1.2 & 60 & 0 & 7.2 & 2.9 \\
\hline HR-CSAV Clarifier & 20 & 15.5 & 52 & 0.172 & 7.0 & 1.4 \\
\hline
\end{tabular}


The HR clarifier was operated at an upflow velocity $15.5 \mathrm{~m} \mathrm{~h}^{-1}$ and total retention time of about 20 minutes (the highest upflow velocity was $25.5 \mathrm{~m} \mathrm{~h}^{-1}$ at retention time of less than 12 minutes). While the residual turbidity at the outlet from all these clarifiers were very similar (around 7 NTU), the optimised aluminium sulphate dosage applied to the HR clarifier was about $15 \%$ lower due to effective agitation than that required by the Clariflocculator and Pretreator to produce same clarity purified water. In addition, the residual turbidity produced by non-separable particles only $C_{C} F=1.2 \mathrm{NTU}$ was measured at the outlet from the HR-CSAV clarifier and $C_{C} F=1.4 \mathrm{NTU}$ from the Pretreator. The Clariflocculator performance was considerably poorer at $C_{C} F=2.7$ NTU. Whilst the attained separation efficiency $\varphi$ for all three clarifiers was very similar around $\varphi=93 \%$ the attainable separation efficiency $\bar{\varphi}$ (benefit of which will be realised during filtration) differed considerably, i.e. Clariflocculator $\bar{\varphi}=96.12 \%$, Pretreator $\bar{\varphi}=97.16 \%$ and HR Clarifier $\bar{\varphi}=98.63 \%$ (Hereit et al., 1980; Polasek, 1980; Mutl, Polasek, 2002; Polasek, Mutl, 2005).

\section{Conclusions}

1. The research into optimisation and acceleration of the water purification process showed the process of formation of aggregates passes through a minimum, which is considered to be the flocculation optimum. This flocculation optimum can be expressed by optimum agitation time $\mathrm{T}$ which is $\bar{G}$, raw water quality and destabilisation agent dependent. Further, this research also showed both the above objectives are interrelated and both can be accomplished by the formation of aggregates with high agitation intensity until flocculation optimum is reached. Furthermore, this research proved the conditions of agitation intensity under which the aggregation of destabilised particles takes place have a decisive effect on the structure and physical properties of the formed aggregates. Too low intensity agitation (the accustomed flocculation conditions) was found to produce aggregates of poorer physical properties and lower settleability. The high intensity agitation (high $\bar{G}$ ) was found to improve settleability of formed aggregates through improving their compactness and thereby density.
2. The high agitation intensity $(\bar{G})$ together with agitation time $(\mathrm{T})$ were found to be the inherent means profoundly influencing the course of the aggregation process and the morphological and physical properties of aggregates formed. Their effect can be summarised as follows:

- $\bar{G}$ determines the maximum size to which aggregate can develop - the maximum attainable aggregate-size decreases with increasing $\bar{G}$,

- $\bar{G}$ and T determine:

- the compactness of the inner structure and thereby the density of aggregates,

- the homogeneity in size and density of the aggregates.

These findings prove the opinion expressed by Han and Lawler (1992), Thomas et al. (1999) and Lawler (2000) in that the importance of velocity gradient has been overestimated in the past, is in conflict with reality.

3. An Inline High Density Suspension (IHDS) aggregation method for the formation of compact and dense aggregates was developed. Under the IHDS process aggregates are formed with a high $\bar{G}>>50 \mathrm{~s}^{-1}$ preferably with $\bar{G}=100$ to $400 \mathrm{~s}^{-1}$ at the flocculation optimum. The $\bar{G}>400 \mathrm{~s}^{-1}$, even though applicable, was found to have no practical or economical benefit.

4. The IHDS method does not change the principles of aggregate formation, i.e. the need for aggregate-destabilisation of the particles of impurities and the mechanisms of formation of flocculent aggregates. It only utilizes, to the utmost benefit, the influence of high intensity movement of aggregates in water for producing the most compact inner structure of the formed aggregates and thereby aggregates of the highest density without the need of applying any floc weighting substance. The resultant micro-aggregates are very dense and homogeneous in size, shape, volume and inner structure. These micro-aggregates are building blocks for the subsequently formed macro-aggregates. Settling velocity of such macro-aggregates is much higher than that of the aggregates formed with low agitation intensity under the accustomed flocculation conditions without the need of applying any floc weighting substance.

5. The velocity gradient $\bar{G}$ and agitation time $T$ influence the morphological and physical properties of aggregates that affect their settleability, whilst the reaction conditions under which the 
aggregation process takes place affect the quality to which the water is treatable.

6 . The IHDS process contributes significantly to the acceleration of the clarification process as comparison of performance results obtained from operation of various type clarifiers have proved.

Acknowledgement. The research project has been funded by the Grant Agency of the Czech Republic under the project No. 103/07/1016 and Institutional Research Plan No. AV0Z20600510. The financial assistance on this project is acknowledged.

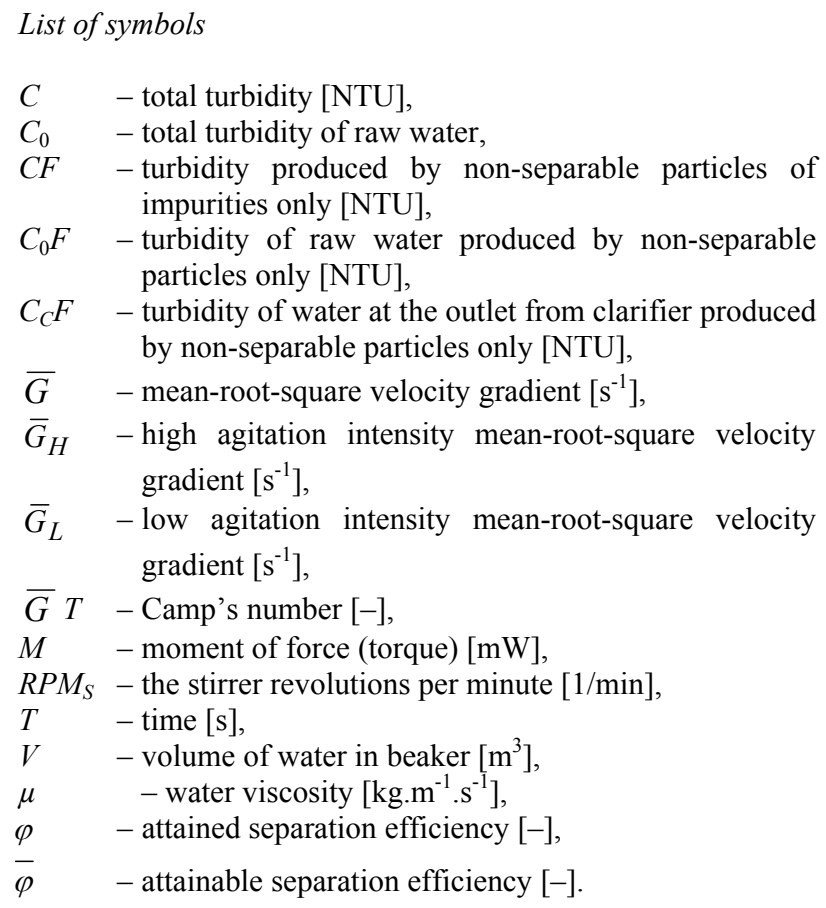

\section{REFERENCES}

CAMP T.R., 1946: Sedimentation and the design of settling tank. Trans. Soc. Civ. Engrs., 895-901.

CAMP T.R., 1953: Flocculation and flocculation basins. Proc. Am. Soc. Civ. Engrs. 79, 283.

CAMP T.R., 1968: Floc volume concentration. JAWWA 60, 656-673.

CAMP T.R. and STEIN P.C., 1943: Velocity gradients and internal work in fluid motion. J. Boston Soc. Civ. Engrs., 4, 219-237.

DUCOSTE J.J. and CLARK M.M., 1998: The influence of tank size and impeller geometry on turbulent flocculation: I. Experimental. Environ. Eng. Sci., 15, 3, 215-224.

FAIR G.M. and GEYER J.C., 1958: Elements of water supply and wastewater disposal. Willey, New York.

HAM R.K. and CHRISTMAN R.F., 1969: Agglomerate size changes in coagulation. J. San. Engng. Div. SA, 3, 95, 481-502.

HAN M.Y. and LAWLER D.F., 1991: Interaction of two settling spheres: settling rates and collision efficiencies. J. Hydraul. Eng. ASCE, 117, 1269-1289.

HAN M.Y. and LAWLER D.F., 1992: The (Relative) Insignificance of $\mathrm{G}$ in flocculation. JAWWA, 84, 79-91.
HARRIS H.S., KAUFMANN W.J. and KRONE R.B., 1966: Orthokinetic flocculation in water purification. Proc. ASCE, J. San. Engng. Div., SA6, 92, 95-111.

HEREIT F., MUTL S. and VAGNER V., 1977: Evalustion of waterworks operation. (In Czech.) Vodní hospodarstvi, 4, rada $\mathrm{B}$.

HUDSON H.R. Jr., 1965: Physical aspects of flocculation. JAWWA, 57, 7, 885-892.

HUDSON H.R. Jr., 1973: Evaluation of plant operating and jar test data. AWWA, 65, 5, 368.

IVES K.J., 1978: The scientific basis of flocculation (Sijthof \& Nordhoff Int. Publishers, Alphen aan der Rijn, Netherlands.

LAWLER D.F., 2000: Theory of particle processes: Changes in size distribution in flocculation, sedimentation and filtration. Proc.Workshop on Particle Counting and Characterization in Drinking Water Treatment, November, Johannesburg, South Africa.

MUTL S., POLASEK P., 2002: Particle Sizes and Particle Size-Fraction Distribution in Water Treatment. Conf. IWA, Poster Paper, April 2002, Melbourne, Australia.

PARKER D.S., KAUFMAN W.J. and JENKINS D., 1972: Floc breakup in turbulent flocculation processes. Proc. ASCE J. San. Engng. Div. SA, 1, 98, 79-99.

POLASEK P., 1970 \& 1972a: Float-Filter, method and apparatus for two-stage treatment of liquids; Water clarification. SA Patents.

POLASEK P., 1980: HR Clarifier performance results. Proc. Int. Conf. SAFIL, Johannesburg.

POLASEK, P., 2005: High Rate Clarification Technology. PPA Johannesburg, Research Report, HRCT 01/72.

POLASEK P., 2007: Differentiation between different kinds of mixing in water purification - back to basics. J. Water SA, $33,2,249-251$

POLASEK, P., 2009: Optimised conditions for application of organic flocculant aids in water purification. J. DWES, paper No. 2009-6 Drink. Water Eng. Sci. Discuss., 2, 205 229, doi: 10.5194/ dwesd-2-205-2009.

POLASEK P. and MUTL S., 1995: Guidelines to coagulation and flocculation for surface water - Volume II: Evaluation of treatment process efficiency of different waterworks Case Studies. PPA, Johannesburg.

POLASEK P. and MUTL S., 2005a: Acceleration of gravity separation process. J. Filtration 5, 1, 33-39.

POLASEK P. and MUTL S., 2005b: High Rate Clarification technology. Proc. IWA Spec. Conf.: Particle Separation 2005, Seoul, South Korea.

POLASEK P. and VAN DUUREN F.A., 1979: Orthokinetic flocculation. Proc. Summer School, University of Pretoria, South Africa.

POLASEK P. and VAN DUUREN F.A., 1981: The performance results from the operation of High Rate Clarifiers at Bethlehem Municipal Waterworks. Proc. Water Industry, 81, Int. Conf. Brighton, UK

RITCHIE A.R., 1965: Certain aspects of flocculation as applied to sewage purification. $\mathrm{PhD}$ Thesis, London, Univ. of London 1955 - cited from Tesarik I. (1968): Discussion to Ives K.: Theory of operation of sludge blanket clarifiers. Proc. Instn. Civ. Engrs, 39, 569.

SCHUTTE F., 2006: Handbook for the operation of Water Treatment Works. Publ. TT 265/06, WRC Pretoria, RSA.

SMOLUCHOVSKI M., 1917: Versuch einer matematischen Theorie der Koagulationskinetik kolloider Lösungen. Z. Physik. Chem. 92, 129. 
SOUCEK J. and SINDELAR J., 1967: The use of a dimensionless criterion in the characterization of flocculation. VUV Praha, Prace a Studie, sesit 112.

SPICER P.T. and PRATSINIS S.E., 1996: Shear induced flocculation: The evaluation of floc structure and the shape of the size distribution at the steady size. Wat. Res., 30, 1049-1056.

SWIFT D.L. and FRIEDLANDER S.K., 1965: The coagulation of hydrosols by Brownian motion and laminar shear flow. J. Colloid Sci., 20, 1070.

TAMBO N. and WATANABE Y., 1979: Physical aspects of flocculation process. I. Fundamental treatise. Wat. Res., 13, 429-439.
THOMAS D.N., JUDD S.J. and FAWCETT N., 1999: Flocculation modelling: A review. Wat. Res. Vol. 33, No. 7, pp. 1579-1592.

VAN DUUREN F.A., 1997: Water Purification Works Design. Publ. TT 92/97, WRC Pretoria, RSA.

WALKER J.D., 1968: High energy flocculation and air-andwater backwashing. JAWWA, 60, 321.

Received 17 March 2010 Accepted 26 October 2010 